\title{
Pre-concentration of mercury from low concentration samples for isotopic analysis
}

\author{
Y. HOSHINO ${ }^{1 *}$, T. OHNO ${ }^{1}$ AND Y. FUKAMI ${ }^{1}$ \\ ${ }^{1}$ Dept. of Chemistry, Gakushuin Univ., Japan, \\ (*correspondence: hoshino.yuri0418@gmail.com)
}

Mercury is a toxic heavy metal that biomagnifies in aquatic food webs. Because $\mathrm{Hg}$ can exhibit both Mass-Dependent (MDF) and Mass-Independent Fractionation (MIF), $\mathrm{Hg}$ isotopes are providing valuable information for tracing pathways and sources of $\mathrm{Hg}$, and specific chemical pathways, such as photochemical reduction [1]. However, it is still challenging to analyze $\mathrm{Hg}$ isotopic compositions in the low concentration samples such as plankton and seaweed which can cause the primary accumulation of $\mathrm{Hg}$ from the seawater. In this study, we developed a new pre-concentration method by Chelex-100 from low concentration samples for $\mathrm{Hg}$ isotopic analysis and investigated the degree of isotopic fractionation during the pre-concentration.

Mercury was separated from other elements in a sample by using Chelex-100 chelating ion-exchange resin, which has functional iminodiacetic acid (IDA) groups in a styrenedivinylbenzene matrix. Firstly, the sample solution was introduced to a column with a condition of $\mathrm{pH}=5$. Subsequently, $\mathrm{Hg}$ was eluted by $6 \mathrm{M} \mathrm{HCl}$. Finally, the concentration of the resultant $\mathrm{Hg}$ solutions was determined by ICP-MS, and $\mathrm{Hg}$ isotopic ratios were measured by Cold VaporMC-ICP-MS. Furthermore, the matrix effect was evaluated by comparing the response of $\mathrm{Hg}$ isotopes in $1.0 \mathrm{M} \mathrm{HCl}$ to those in $0.1,0.5$, and $2.0 \mathrm{M} \mathrm{HCl}$, respectively.

The sample in $0.5 \mathrm{M} \mathrm{HCl}$ showed no significant isotope fractionation compared to that in $1.0 \mathrm{M} \mathrm{HCl}$. We obtained the value of $\delta^{202} \mathrm{Hg}$ of $-0.34 \pm 0.15 \%$ and $0.2 \pm 0.4 \%$ when the sample solutions were adjusted to 2.0 and $0.1 \mathrm{M} \mathrm{HCl}$, respectively. Consequently, the sample solutions should be adjusted to $0.5-1.0 \mathrm{M} \mathrm{HCl}$ to reduce the acid matrix effect when measuring $\mathrm{Hg}$ isotopic ratios. The recovery of the preconcentration protocol was $>95 \%$ in the final $\mathrm{Hg}$ eluates. The $\delta^{202}$ and $\Delta^{199}$ values for $\mathrm{Hg}$ reference solution processed by the pre-concentration protocol were $0.09 \pm 0.12 \%$ and $-0.01 \pm$ $0.03 \%$, suggesting no isotopic fractionation during the preconcentration. In conclusion, the present study demonstrated that the developed method could be a useful tool for $\mathrm{Hg}$ isotope analysis.

[1] B. A. Bergquist and J. D. Blum, Science, 318, 417, (2007) 